\title{
Review of air pollution and health impacts in Malaysia
}

\begin{abstract}
In the early days of abundant resources and minimal development pressures, little attention was paid to growing environmental concerns in Malaysia. The haze episodes in Southeast Asia in 1983, 1984, 1991, 1994, and 1997 imposed threats to the environmental management of Malaysia and increased awareness of the environment. As a consequence, the government established Malaysian Air Quality Guidelines, the Air Pollution Index, and the Haze Action Plan to improve air quality. Air quality monitoring is part of the initial strategy in the pollution prevention program in Malaysia. Review of air pollution in Malaysia is based on the reports of the air quality monitoring in several large cities in Malaysia, which cover air pollutants such as Carbon monoxide (CO), Sulphur Dioxide (SO2), Nitrogen Dioxide (NO2), Ozone (O3), and Suspended Particulate Matter (SPM). The results of the monitoring indicate that Suspended Particulate Matter (SPM) and Nitrogen Dioxide (NO2) are the predominant pollutants. Other pollutants such as $\mathrm{CO}, \mathrm{Ox}, \mathrm{SO}$, and $\mathrm{Pb}$ are also observed in several big cities in Malaysia. The air pollution comes mainly from land transportation, industrial emissions, and open burning sources. Among them, land transportation contributes the most to air pollution. This paper reviews the results of the ambient air quality monitoring and studies related to air pollution and health impacts.
\end{abstract}

Keyword: Air pollution; Sources of air pollution; Air quality; Ambient air quality guideline; Health impact 